\title{
Prevalence of BRAF V600E Mutation in the Iranian Patients with Hairy Cell Leukemia: A Retrospective Study
}

\author{
Mojatba Karimi ${ }^{1}$, Ahmad Monabbati², Nasibe Sargazi Moghaddam ${ }^{3}$
}

${ }^{1}$ Department of Hematology and Medical Oncology, Shiraz University of Medical Sciences, Shiraz, Iran. ${ }^{2}$ Department of Pathology, Shiraz University of Medical Sciences, Shiraz, Iran. ${ }^{3}$ Faculty of Medicine, Shiraz University of Medical Sciences, Shiraz, Iran.

\begin{abstract}
Objective: BRAF V600E mutation has several implications in hairy cell leukemia (HCL). The prevalence of This mutation has been investigated in various populations, but not in Iran. In this study, we evaluated the prevalence of BRAF V600E mutation in an Iranian HCL population as well as its association with the patients' characteristics. Methods: In a retrospective (archival) study, 20 HCL patients with the confirmed immunophenotypic and morphologic diagnosis were included. Paraffin-embedded blocks of bone marrow aspirate were used to investigated BRAF V600E mutation using amplification refractory mutation system (ARMS) PCR. Demographic, clinical, laboratory, and immunophenotypic characteristics of patients were extracted from the patients medical profiles. Result: BRAF V600E mutation was present in $17(85 \%)$ HCL patients and absent in three (15\%) patients. The mean age of the patients was $44.76 \pm 8.69$ years in mutation-positive and $62.33 \pm 8.69$ in mutation-negative patients. This difference was statistically significant $(\mathrm{p}=0.013)$. No significant difference was found between the laboratory indices of the mutation-positive and mutation-negative groups. The clinical, morphologic, and immunophenotypic characteristics of the two groups were also statistically comparable. Conclusion: BRAF V600E mutation is present in the majority of the Iranian HCL patients and is associated with younger age of presentation.
\end{abstract}

Keywords: BRAF V600E- Hairy Cell Leukemia- Mutation

Asian Pac J Cancer Biol, 6 (2), 141-145

\section{Introduction}

Hairy cell leukemia (HCL) is a rare and slow-growing hematological malignancy with unknown etiology, accounting for $2 \%$ of all leukemias. It is a very heterogeneous group of B-cell disorders characterized by excessive B-cell proliferation in the bone marrow with a hairy look under the microscope. The patients are generally presented with pancytopenia and splenomegaly, as well as non-specific clinical symptoms such as fatigue and weakness [1]. Although the etiology of HCL is not well identified, a connection between specific gene mutations has been elucidated [2].

MAP kinase cascade is a key signaling pathway that mediates a wide variety of cellular functions, including cellular growth, proliferation, differentiation, and apoptosis. Activation of the MAP kinase pathway is a frequent event in tumorigenesis. The BRAF gene is
Submission Date: 03/31/2021 Acceptance Date: 05/14/2021

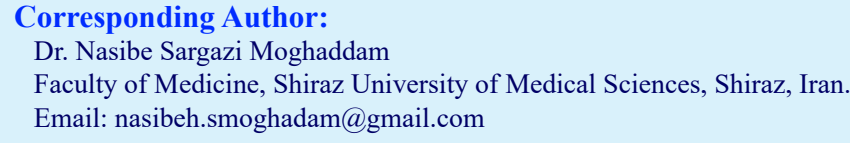

a human gene with different variant products involved in the MAPK pathway and its mutation might lead to uncontrolled cell proliferation. About 43 mutations have been identified in the BRAF gene, which has been attributed to a variety of human malignancy [3-4].

$\mathrm{V} 600 \mathrm{E}$ is the most common mutation of BRAF (BRAF $\mathrm{V} 600 \mathrm{E}$ ), which occurs on exon 15 and results in the alteration of amino acid 600 from valine to glutamate in the BRAF protein, followed by continuous activation of the downstream kinases and increased cell proliferation [5]. BRAF V600E has been detected in various cancers with different prevalence including colorectal cancers (about $10 \%$ of cases), non-small cell lung cancers (about $7 \%$ of cases), papillary thyroid cancers (about $51 \%$ of cases), and melanoma (about $50 \%$ of cases) [6].

Although BRAF V600E mutation has been identified 
in over $97 \%$ of the HCL cases so far investigated [7], a lower frequency of BRAF mutations (79\%) has also been reported [8]. Considering the implications of BRAF V600E mutation for the pathogenesis, diagnosis, prognosis, and targeted therapy of HCL, evaluation of its prevalence in different HCL populations is of critical importance [4]. However, the prevalence of BRAF V600E mutation in the Iranian HCL population has not been studied in earlier investigations. In this multi-center study, we evaluate the prevalence of BRAF V600E mutation in Iranian HCL patients.

\section{Materials and Methods}

\section{Study design and data collection}

This retrospective (archival) study was approved by the review board of our institute. The target population was consecutive HCL patients who were referred to the oncology hospitals of Shiraz, Iran, between 2012 and 2015. Patients with a confirmed immunophenotypic and morphologic diagnosis of HCL were included, providing that their paraffin-embedded block of bone marrow aspirate was available for genetic evaluation. Finally, 20 patients were identified as eligible for the study. Demographic, clinical, laboratory, and immunophenotypic characteristics of patients were extracted from the patients medical profiles.

\section{Evaluation of BRAF V600E mutation}

After deparaffinization of paraffin-embedded sections, DNA was extracted using GeNet Bio kit (GeNet Bio inc. Daejeon, South Korea). The quality and quantity of DNA were assessed with a nanodrop-1000 spectrophotometer. Then DNA amplification was done using amplification refractory mutation system-polymerase chain (ARMSPCR) as earlier described [9]. The ARMS-PCR primer sequences are demonstrated in Table 1.

Four PCR primers were included in one PCR tube. Accordingly, F-R primer pair amplifies a common 200 bp fragment flanking the site of mutation. F-Rmi primer pair amplifies a fragment of $144 \mathrm{bp}$ specific to the BRAF V600E mutation. Fwi-R primer pair amplifies a $97 \mathrm{bp}$ fragment specific to wild-type BRAF gene.

PCR was performed in a $25 \mu \mathrm{l}$ final volume, which included $1 \times$ Buffer, $30 \mathrm{ng}$ extracted DNA template, $2 \mathrm{mM}$ $\mathrm{MgCl} 2,1$ unit of Hotstar Taq DNA polymerase (Qiagen Science, Valencia, CA), $200 \mu \mathrm{M}$ of dNTPs, $400 \mathrm{nM}$ primer F, $200 \mathrm{nM}$ primer R, $200 \mathrm{nM}$ primed Fwi, and $800 \mathrm{nM}$ primer Rmi. PCR was started with denaturation at $95^{\circ} \mathrm{C}$ for $5 \mathrm{~min}$, followed by 40 cycles of $94^{\circ} \mathrm{C}$ for $20 \mathrm{sec}, 62^{\circ} \mathrm{C}$ for $20 \mathrm{sec}$ and $72^{\circ} \mathrm{C}$ for $20 \mathrm{sec}$, and a final extension step at $72^{\circ} \mathrm{C}$ for $5 \mathrm{~min}$. PCR products were analyzed by $2.5 \%$ agarose gel electrophoresis and were visualized under
UV light (Figure 1).

\section{Statistical analysis}

SPSS for Windows version 16 (SPSS Inc., Chicago, Ill., USA) was used for the statistical analysis of the data. Descriptive statistics were demonstrated with mean \pm standard deviation or number $\&$ percentage. A Mann-Whitney U test was used to compare quantitative variables across two groups. A chi-square test was used to evaluate the statistical association between categorical variables. A p-value of fewer than 0.05 was considered statistically significant.

\section{Results}

The study population included $19(95 \%)$ males and one $(5 \%)$ female with a mean age of $47.4 \pm 10.3$ years (range 28-66). BRAF V600E mutation was positive in 17 (85\%) patients and negative in three $(15 \%)$ patients. The mean age of the patients was significantly lower in patients with positive BRAF V600E mutation ( $\mathrm{p}=0.013)$. No other significant association was found between the patients with and without BRAF V600E mutation. Laboratory indices were also statistically comparable between the two groups (Table 2).

The mean size of the spleen was $18.7 \pm 2.3 \mathrm{~cm}$ in the negative and $17.4 \pm 3.5 \mathrm{~cm}$ in the positive BRAF V600E mutation group $(\mathrm{p}=0.416)$. Accordingly, splenomegaly was noticed in one patient of the positive BRAF V600E group and no patient of the negative BRAF V600E group $(\mathrm{p}=0.666)$. No other significance was also found between the clinical features of the two groups. Bone marrow imorphology was statistically comparable between the two groups, as well (Table 3). Moreover, no significant difference was found between the immunophenotypic characteristics of the two groups (Table 4).

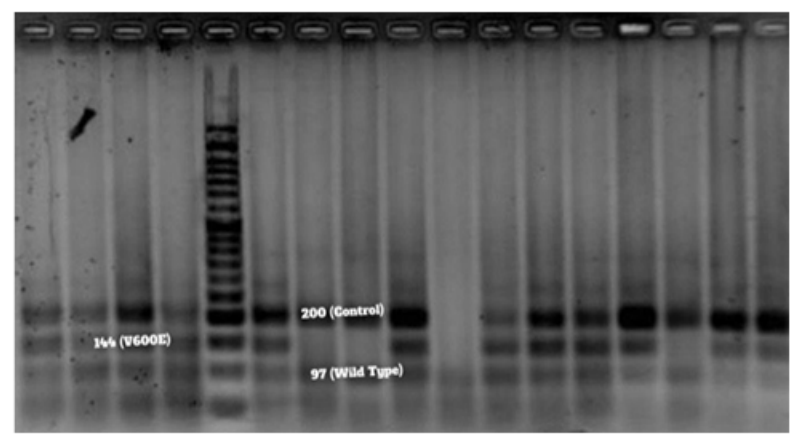

Figure 1. Evaluation of PCR Products on the Agarose Gel Electrophoresis under UV Light

Table 1. The ARMS-PCR primer sequences for the detection of BRAF V600E

\begin{tabular}{ll}
\hline Forward (F) & 5'-CTC TTC ATA ATG CTT GCT CTG ATA G-3' \\
\hline Reverse (R) & 5'-GCCTCAATTCTTACCATCCAC-3' \\
Forward wild-type identifying (Fwi) & 5'-GTGATTTTGGTCT AGCTACAGT-3' \\
Reverse mutation identifying: (Rmi) & 5'-CCCACTCCATCGAGATTTCT-3' \\
\hline
\end{tabular}


Table 2. Comparison of Demographic and Laboratory Characteristics between BRAF V600E Positive and Negative Patients

\begin{tabular}{lccc}
\hline Variables & \multicolumn{2}{c}{ BRAF Gene Mutation } & P-value \\
\hline Sex & Negative $(\mathrm{n}=3)$ & Positive $(\mathrm{n}=17)$ & 0.666 \\
$\quad$ Male & $3(100)$ & $16(94.1)$ & $0.013^{*}$ \\
$\quad$ Female & 0 & $1(5.9)$ & 0.468 \\
Age (years) & $62.33 \pm 8.69$ & $44.76 \pm 8.69$ & 0.356 \\
WBC count $(/ \mu \mathrm{L})$ & $2733 \pm 2020$ & $2241 \pm 868$ & 0.364 \\
Neutrophil $(\%)$ & $50 \pm 18$ & $39 \pm 18$ & 0.91 \\
Lymphocyte $(\%)$ & $50 \pm 18$ & $60 \pm 18$ & 0.149 \\
Hemoglobin $(\mathrm{g} / \mathrm{dL})$ & $9.8 \pm 4.2$ & $9.9 \pm 1.7$ & $55411 \pm 26260$ \\
Platelet count $(/ \mu \mathrm{L})$ & $81000 \pm 32908$ & & \\
\hline
\end{tabular}

Data are presented as mean \pm SD or number $(\%) . \mathrm{P}<0.05$ is considered significant.

Table 3. Comparison of Clinical and Morphologic Features between BRAF V600E Positive and Negative Patients

\begin{tabular}{|c|c|c|c|}
\hline \multirow[t]{2}{*}{ Variables } & \multicolumn{2}{|c|}{ BRAF gene mutation } & \multirow[b]{2}{*}{ P-value } \\
\hline & Negative $(n=3)$ & Positive $(n=17)$ & \\
\hline \multicolumn{4}{|l|}{ Hospital Admissions } \\
\hline - Once & 0 & $2(11.8)$ & \\
\hline Twice \& More & $3(100)$ & $12(70.6)$ & 0.555 \\
\hline$\cdot$ Never & 0 & $3(17.6)$ & \\
\hline Spleen size $(\mathrm{cm})$ & $18.7 \pm 2.3$ や & $17.4 \pm 3.5$ や & 0.416 \\
\hline \multicolumn{4}{|l|}{ Splenomegaly } \\
\hline$\cdot$ Yes & 0 & $1(5.9)$ & 0.666 \\
\hline$\cdot$ No & $3(100)$ & $16(94.1)$ & \\
\hline \multicolumn{4}{|c|}{ Bone marrow Morphology } \\
\hline$\cdot$ Hypocellular & $2(66.7)$ & $5(29.4)$ & \\
\hline$\cdot$ Hypercellular & 0 & $3(17.6)$ & 0.42 \\
\hline - Mosaic-pattern & $1(33.3)$ & $9(53)$ & \\
\hline
\end{tabular}

Data are presented as mean \pm SD or number $(\%) . \mathrm{P}<0.05$ is considered significant.

\section{Discussion}

In this study, we evaluated the presence of BRAF V600E mutation in Iranian HCL patients in a metacentric study. We also investigated the association of this mutation with the patients' characteristics. According to this study, BRAF V600E mutation was present in $85 \%$ of HCL patients. Patients with negative BRAF V600E mutation had significantly higher age. No significant association was found between the BRAF V600E mutation and characteristics of HCL patients such as laboratory indices, immunophenotypic markers, etc.

In earlier studies, various rates have been reported for BRAF V600E mutation in HCL patients. Tiacci et al. evaluated the BRAF V600E mutation in 47 Italian HCL patients. BRAF V600E mutation was present in all patients [4]. Boyd et al. reported 100\% BRAF V600E mutation ( $\mathrm{n}=48)$ in English HCL patients [10]. Arciani et al. assessed BRAF V600E mutation in $62 \mathrm{HCL}$ patients. BRAF V600E mutation was detected in all cases [11]. Blombery et al. investigated BRAF V600E mutation in 51 Australian HCL patients (59 samples). In total, BRAF
V600E mutation was detected in 36 out of 51 patients $(70.5 \%)$ [12]. Bibi et al. detected BRAF V600E mutation in $89.1 \%$ (41/46 patients) of the Indian HCL population [11]. In the present study, we detected BRAF V600E mutation in $85 \%$ of Iranian HCL patients that was similar to that reported in the study of Bibi et al [11]. Nonetheless, the difference between studies could be attributed to the method of detection. Blombery et al. used high resolution melting analysis and confirmatory Sanger sequencing for the detection of BRAF V600E mutation. The detected mutations were not equal using the two methods, so that high resolution melting analysis detected mutation in 42 samples, which was confirmed by sequencing in 38 [12]. Therefore, the method of evaluation could be regarded as a source of heterogeneity between the studies.

Langabeer et al. evaluated the correlation of the BRAF V600E mutation with immunophenotypic characteristics of the 24 patients with a classic HCL. The CD11c+/CD20+/ CD25+/CD103+/FMC7+ HCL immunophenotype was detected in $23 \mathrm{HCL}$ patients. BRAF V600E mutation was also detected in 23 patients. They suggested a high degree of correlation between the presence of BRAF 
Table 4. Distribution of Immunophenotypic Markers According to BRAF Gene Mutation (when the sum of subsets is not equal to the total patients' number, there is missing data)

\begin{tabular}{|c|c|c|c|}
\hline \multirow[t]{2}{*}{ Variables } & \multicolumn{2}{|c|}{ BRAF gene mutation } & \multirow[t]{2}{*}{ P-value } \\
\hline & Negative $(n=3)$ & Positive ( $\mathrm{n}=17$ ) & \\
\hline \multicolumn{4}{|l|}{ CD3 } \\
\hline - Positive & $1(33.3)$ & $2(18.2)$ & 0.571 \\
\hline$\cdot$ Negative & $2(66.7)$ & $9(81.8)$ & \\
\hline \multicolumn{4}{|l|}{ CD5 } \\
\hline - Positive & 0 & $2(16.7)$ & 0.666 \\
\hline$\cdot$ Negative & $2(100)$ & $12(83.3)$ & \\
\hline \multicolumn{4}{|l|}{ CD7 } \\
\hline - Positive & 0 & $2(100)$ & 0.083 \\
\hline$\cdot$ Negative & $1(100)$ & 0 & \\
\hline \multicolumn{4}{|l|}{ CD8 } \\
\hline - Positive & $1(100)$ & $2(66.7)$ & 0.505 \\
\hline - Negative & 0 & $1(33.3)$ & \\
\hline \multicolumn{4}{|l|}{ CD10 } \\
\hline - Positive & 0 & $2(20)$ & 0.621 \\
\hline - Negative & $1(100)$ & $8(80)$ & \\
\hline \multicolumn{4}{|l|}{ CD11c } \\
\hline - Positive & $2(100)$ & $16(94.1)$ & 0.725 \\
\hline - Positive focally & 0 & $1(5.9)$ & \\
\hline \multicolumn{4}{|l|}{ CD19 } \\
\hline - Positive & $2(100)$ & $7(87.5)$ & 0.598 \\
\hline - Negative & 0 & $1(12.5)$ & \\
\hline \multicolumn{4}{|l|}{$\mathrm{CD} 20$} \\
\hline - Positive & $1(33.3)$ & $11(64.7)$ & 0.306 \\
\hline - Positive diffusely & $2(66.7)$ & $6(35.3)$ & \\
\hline \multicolumn{4}{|l|}{ FMC7 } \\
\hline - Positive & 0 & $1(100)$ & 0.157 \\
\hline - Negative & $1(100)$ & 0 & \\
\hline
\end{tabular}

Data are presented as number (\%). $\mathrm{P}<0.05$ is considered significant.

V600E mutation and established diagnostic criteria and highlighted the value of a multifaceted approach to the diagnosis of HCL [13]. We could not detect the association between BRAF V600E mutation and immunophenotypic characteristics due to the high missing data in this section.

In the study of Bibi et al. HCL patients with BRAF V600E mutation presented at a younger age. However, no significant difference was found between the other characteristic features of the patients with and without BRAF mutation, such as in laboratory parameters [14]. We also detected an association between BRAF V600E mutation and the age of the presentation, so that patients with BRAF V600E mutation were significantly younger. Similar to the study of Bibi et al. laboratory indices were not associated with BRAF V600E mutation in the present study.

The present study has several weaknesses. First, the PCR results were not confirmed by sequencing. Second, the number of patients in the negative BRAF mutation group was considerably small. Therefore, the power of statistical analysis could be poor. Finally, a significant number of data were missing, particularly in immunophenotypic characteristics. Therefore, future studies with larger patients' numbers are required to confirm the results of this study.

In conclusion, BRAF V600E mutation was present in $85 \%$ of Iranian HCL patients and absent in $15 \%$. The presence of the mutation was associated with the younger age of the patients, but not with other patients' characteristics such as immunophenotypic and laboratory indices. Our finding suggests a diagnostic role for BRAF V600E mutation in the Iranian HCL population.

\section{Acknowledgements}

We would like to thank the Shiraz University of Medical Sciences for providing the infrastructure and implications for this study, and we would especially like to thank Mrs. Valibegi, a medical school technician, for all her efforts and support during this study. 


\section{Funding Statement}

This thesis is supported by deputy dean of School of Medicine based on research project number 7008 dated 1392/1/1 and sponsored by deputy chancellor of Shiraz University of Medical Sciences.

\section{Statement conflict of Interest}

No potential conflict of interest was reported by the authors.

\section{References}

1. Troussard X, Cornet E. Hairy cell leukemia 2018: Update on diagnosis, risk-stratification, and treatment. American Journal of Hematology. 2017 Nov 07;92(12):1382-1390. https://doi.org/10.1002/ajh.24936

2. Durham BH, Getta B, Dietrich S, Taylor J, Won H, Bogenberger JM, Scott S, Kim E, Chung YR, Chung SS, Hüllein J, Walther T, Wang L, Lu SX, Oakes CC, Tibes R, Haferlach T, Taylor BS, Tallman MS, Berger MF, Park JH, Zenz T, Abdel-Wahab O. Genomic analysis of hairy cell leukemia identifies novel recurrent genetic alterations. Blood. 2017 Oct 05;130(14):1644-1648. https://doi. org/10.1182/blood-2017-01-765107

3. Ahmadzadeh A, Shahrabi S, Jaseb K, Norozi F, Shahjahani M, Vosoughi T, Hajizamani S, Saki N. BRAF mutation in hairy cell leukemia. Oncology Reviews. 201409 23; https://doi. org/10.4081/oncol.2014.253

4. Tiacci E, Trifonov V, Schiavoni G, Holmes A, Kern W, Martelli MP, Pucciarini A, Bigerna B, Pacini R, Wells VA, Sportoletti P, Pettirossi V, Mannucci R, Elliott O, Liso A, Ambrosetti A, Pulsoni A, Forconi F, Trentin L, Semenzato G, Inghirami G, Capponi M, Di Raimondo F, Patti C, Arcaini L, Musto P, Pileri S, Haferlach C, Schnittger S, Pizzolo G, Foà R, Farinelli L, Haferlach T, Pasqualucci L, Rabadan R, Falini B. BRAFMutations in Hairy-Cell Leukemia. New England Journal of Medicine. 201106 16;364(24):2305-2315. https:// doi.org/10.1056/nejmoa1014209

5. Dhomen N, Marais R. New insight into BRAF mutations in cancer. Current Opinion in Genetics \& Development. 2007 02;17(1):31-39. https://doi.org/10.1016/j.gde.2006.12.005

6. Morris VK, Bekaii-Saab T. Improvements in Clinical Outcomes for BRAFV600E-Mutant Metastatic Colorectal Cancer. Clinical Cancer Research. 202004 06;26(17):44354441. https://doi.org/10.1158/1078-0432.ccr-19-3809

7. Falini B, Martelli MP, Tiacci E. BRAF V600E mutation in hairy cell leukemia: from bench to bedside. Blood. 2016 Oct 13;128(15):1918-1927. https://doi.org/10.1182/ blood-2016-07-418434

8. Xi L, Arons E, Navarro W, Calvo KR, Stetler-Stevenson M, Raffeld M, Kreitman RJ. Both variant and IGHV434-expressing hairy cell leukemia lack the BRAF V600E mutation. Blood. 201204 05;119(14):3330-3332. https:// doi.org/10.1182/blood-2011-09-379339

9. Huang T, Zhuge J, Zhang WW. Sensitive detection of BRAF V600E mutation by Amplification Refractory Mutation System (ARMS)-PCR. Biomarker Research. 201301 16;1(1). https://doi.org/10.1186/2050-7771-1-3

10. Boyd EM, Bench AJ, van 't Veer MB, Wright P, Bloxham DM, Follows GA, Scott MA. High resolution melting analysis for detection of BRAF exon 15 mutations in hairy cell leukaemia and other lymphoid malignancies. British Journal of Haematology. 201109 13;155(5):609-612. https:// doi.org/10.1111/j.1365-2141.2011.08868.x

11. Arcaini L, Zibellini S, Boveri E, Riboni R, Rattotti S,
Varettoni M, Guerrera ML, Lucioni M, Tenore A, Merli M, Rizzi S, Morello L, Cavalloni C, Da Vià MC, Paulli M, Cazzola M. The BRAF V600E mutation in hairy cell leukemia and other mature B-cell neoplasms. Blood. $20120105 ; 119(1): 188-191$. https://doi.org/10.1182/ blood-2011-08-368209

12. Blombery PA, Wong SQ, Hewitt CA, Dobrovic A, Maxwell EL, Juneja S, Grigoriadis G, Westerman DA. Detection of BRAF mutations in patients with hairy cell leukemia and related lymphoproliferative disorders. Haematologica. 2011 Dec 01;97(5):780-783. https://doi.org/10.3324/ haematol.2011.054874

13. Langabeer SE, O'brien D, Liptrot S, Flynn CM, Hayden PJ, Conneally E, Browne PV, Vandenberghe E. Correlation of the Brafv600e mutation in hairy cell leukaemia with morphology, cytochemistry and immunophenotype. International Journal of Laboratory Hematology. 2012 02 07;34(4):417-421. https://doi.org/10.1111/j.1751553x.2012.01402.x

14. Patkar N, Bibi A, Java S, Chaudhary S, Joshi S, Mascerhenas R, Rabade N, Tembhare P, Subramanian P, Gujral S, Menon H, Khattry N, Sengar M, Bagal B, Jain H. Brafv600e mutation in hairy cell leukemia: A single-center experience. Indian Journal of Pathology and Microbiology. 2018;61(4):532. https://doi.org/10.4103/ijpm.ijpm_484_16

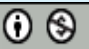

This work is licensed under a Creative Commons AttributionNon Commercial 4.0 International License. 